\section{Original Research}

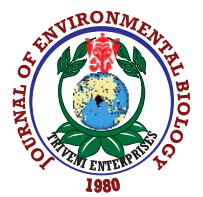

DOI : http://doi.org/10.22438/jeb/41/2(SI)/JEB-28
Journal Home page : www.jeb.co.in ^ E-mail : editor@jeb.co.in Journal of Environmental Biology

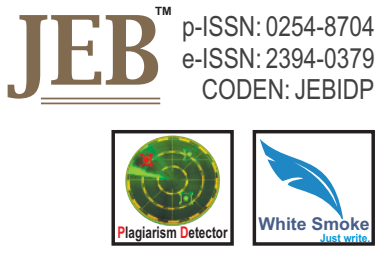

\title{
Attitude of hunters on snake habitat and management system in Cyprus
}

\author{
S. Ilseven ${ }^{1 *}$, Z. Nasrullah ${ }^{2}$ and F. Aslanova ${ }^{3}$ \\ ${ }^{1}$ Art and Science Faculty, Near East University Nicosia, Mersin 10, 99138, Turkey \\ ${ }^{2}$ Environmental Science Faculty, University of Peshawar, Peshawar, 25120, Pakistan \\ ${ }^{3}$ Civil and Environmental Engineering Faculty,Near East University Nicosia, Mersin 10, 99138, Turkey \\ *Corresponding Author Email : silseven66@hotmail.com
}

\section{Abstract}

Aim: Turkish Republic of Northern Cyprus is home to a number of snake species. This study aimed to investigate the effect of hunting on snakes in Northern Cyprus.

Methodology: Questionnaire was developed which had both qualitative and quantitative sections. The questionnaire was filled with personal interviews with hunters of old and young generations. Moreover, people from various fields were also interviewed for this purpose. Once the questionnaire was developed, specific public from the study area were identified.

Results: Most hunters know about the Blunt nosed viper (Macrovipera lebetina) as the only poisonous specie on the island but they only had the knowledge of 3 or 4 species so they mostly get confused Blunt nosed viper with other species like Coin snake (Hemorrhois nummifer), Cat snake (Telescopus fallax) and Large whip snake (Typhlops vermicularis) during sexual maturity. Most hunters think Co in snake is also poisonous due to its similarity with Blunt nosed viper. Cat snake is also thought to be poisonous among some hunters. Mostly, the grey and dotted, square or ring like patterns is considered as poisonous snake. Coin snake is the main victim of killing due to its similarity with the Blunt nosed viper.

Interpretation: Most hunters know that snake population is decreasing day by day and hunting is the biggest threat to them. Due to vigorous hunting on small island, the snakes are being targeted by the hunters. The second major threat is habitat loss due to land use.

Key words: Hunters, Northern Cyprus, Snake habitat

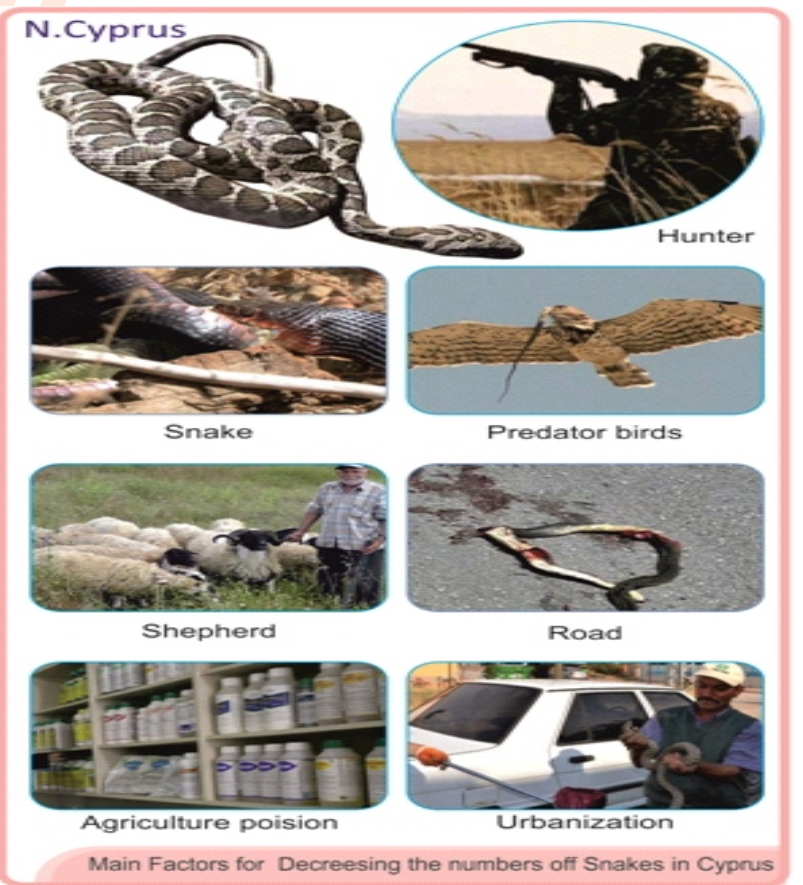

How to cite : Illseven, S., Z. Nasrullah and F. Aslanova: Attitude of hunters on snake habitat and management system in Cyprus. J. Environ. Biol., 41, 475-482 (2020). 


\section{Introduction}

Environmental issues are being given increasing importance throughout the world during recent times. All the major problems are connected with each other as thread hold, impacting one another. One of the major concern is loss of biodiversity. Biodiversity is affected by other issues such as deforestation, climate change, urbanization, natural resource depletion and over population (Kilbert, 2000). Loss of biodiversity mainly due to urbanization affects all kind of species. The reduced number is due do different environmental issues, which finally leads to extinction of specie. Reptiles are also affected by environmental issues and are constantly decreasing in numbers. Most of them have been enlisted as endangered species. Snake population is one of the most affected groups among reptiles, however, with their decreasing population there are number of social issues along with the environmental issues (Pimm et al., 1995). Lack of biodiversity threatens long-term firmness of this modern society (Chapin et al., 2000). Even though international extinctions or disappearance have a root reason, i.e., in particular growing human populace, the mechanisms that threaten the population are pushed extinct are complicated, numerous, and synergistic (Forester and Machlis, 1996). Commonly, anthropogenic traits consisting of agriculture, housing, and transportation infrastructure result in dropping and fragmentation of habitat that is utilized by different species. This lack of connectivity lead to decrease in genetic diversity and inbreeding despair in affected population, making them liable to illnesses and stochastic environmental events (Frankham et al., 2002).

Human influences (Anthropogenic influences) are also causing a boom in frequency of stochastic environmental activities via mechanisms along with altered wildfire regimes, invasive species creation, and weather change (Coblentz, 1990; Meehl et al., 2000; Syphard et al., 2007). These anthropogenic disturbances change the structure and functioning of the biodiversity (flora and fauna) which adversely affect the soil system as well as whole forest / ecosystem (Kadeba and Aduayi 1985; Bargali et al., 1992a and b; Bargali et al., 1993; Joshi et al., 1997; Bargali and Singh 1997a and b). The worldwide biodiversity crisis has acquired good sized interest during last decade (Pickett et al., 1997). The decline of some vertebrate taxa has been documented, especially mammals, birds and lately amphibians. However, as a set, squamate reptiles (lizards and snakes) have received less attention (Dodd, 1987; 1993). Its miles broadly diagnosed that know-how distribution and abundance of organisms on the subject of variation in ecological factors is a crucial step in control. Despite the fact that the ecological relationship of lizards were tested in a few element over the past 30 years (Pianka, 1986), snakes have obtained rather little interest in this regard (Vitt, 1987).

Reptiles are 250 million year old specie that appeared in late Palaeozoic Era (Hedges and Poling, 1999). Reptiles like snakes have evolved extensively adapting to almost varied temperature, tropical and desert environment, and to terrestrial, freshwater and marine habitats. Reptiles play a vital role in natural structures, as predators, prey, grazers, seed dispersers and commensal species; they serve as bioindicator for environmental fitness, and their regular unique microhabitat associations offer perfect look at machine to illustrate the biological and evolutionary processes underlying speciation (Raxworthy et al., 2008; Read, 1998).

Snakes usually have narrower distributional levels than other vertebrates along with birds and mammals (Anderson, 1984; Anderson and Marcus, 1992), making them extra prone to hazard techniques, but there's a few marked version in variety length among special clades of reptiles (Anderson and Marcus, 1992). This combination of small variety and narrow area of interest necessities make reptiles prone to anthropogenic risk. Regional tests in Europe (Cox and Temple, 2009) and southern Africa (South Africa, Lesotho and Swaziland; Bates et al., in press) suggest that $1 / 5^{\text {th }}$ and $1 / 10^{\text {th }}$ of reptilian species are at the verge of extinction. It has additionally been proposed that reptilian declines are comparable in taxonomic breadth, geographic scope and severity to those presently found in amphibians (Gibbons et al., 2000). Decline in reptile population has been attributed to habitat loss and degradation, in addition to unsustainable exchange, invasive species, pollution, disorder and climate exchange (Cox and Temple, 2009; Gibbons et al., 2000; Todd et al., 2010). In all 9,084 species of reptiles have been described (Uetz, 2010), and new molecular evidence continues to unearth severa cryptic species that have not been previously detected through morphological analyses (Adalsteinsson et al., 2009; Nagy et al., 2012; Oliver et al., 2009). Reptiles are perhaps one of the least studied vertebra as $65 \%$ of reptiles have now not been evaluated in IUCN purple listing checks (Böhm et al., 2013). Additionally, of these species that have been evaluated, $20 \%$ of them were deemed facts deficient (Böhm et al., 2013). That is troubling given latest concerns that reptiles perhaps experiencing worldwide declines on par with the ones in other taxa (Gibbons et al., 2000; Böhm et al., 2016). Among reptiles, snakes perhaps high-quality epitomize the hassle of each a extensive lack of statistics and current enigmatic declines across several continents (Winne et al., Todd et al., 2010). accordingly, figuring out which traits in snakes are associated with sensitivity to human land use described here as the absence of a species from humandominated landscapes, either because of habitat selection or due to local extirpations may offer well timed statistics to save you declines of those regularly omitted or understudied species.

\section{Materials and Methods}

This research is based on the social survey which aims at finding out general information about snakes and the reasons behind declining population of snakes. This study aimed to investigate the attitude of hunters towards snake's habitat due to 
Demography

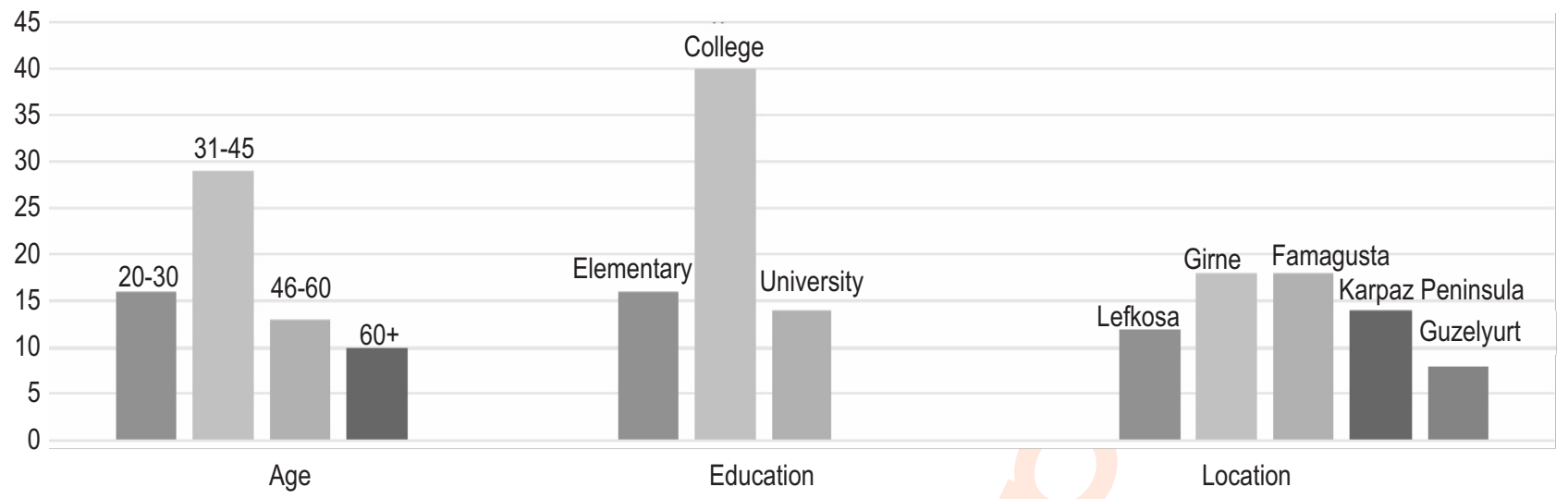

Fig. 1 : Demographic distribution.

snake population decline and the management system of snake habitat in Cyprus. Questionnaire was prepared which had both qualitative and quantitative sections. The questionnaire was filled in personal interviews with hunters of old generation and young generation. Moreover people from various fields were also interviewed for this purpose. Once the questionnaire was developed, specific public from the study area were identified. Simple random sampling was used for interviewing purpose. They were hunters, primitive people, or belonged to specific related departments like wildlife or environmental education. These people were then interviewed with in person in a time period of three months. They were asked about their personal information like age, area, profession, education level etc. Some of the highlighted questions from the questionnaire included: Their knowledge about the number of snake species, their names, and nature. Why their population is declining or increasing? What is the impact of hunters on snakes? During research it was deemed that qualification of the study group was appropriate, the participants have answered all the queries frankly and correctly, and sufficient data is retrieved from literature. Total one hundred questionnaires were filled. Data was then compiled and was analyzed statistically by using SPSS 20.0.

Fig. 1 shows demographic distribution. Hunters between the age of $25-30,31-45,46-60$, and 60 above were $16,29,13$ and 10 , respectively. 40 hunters had college level education, 16 just had elementary level while 14 respondents had university level education. They were 12 hunters from Lefkosa and its surrounding areas, 18 from Girne and Lapta region 18 from Famagusta and its surrounding areas 14 from Karpaz region and 8 from Guzelyurt.

\section{Results and Discussion}

This study explain the results obtained from respondents answer to the questionnaire and then discussed according to the outcome of analyses

\section{How many snake species are present in North Cyprus?}

Table 2 shows the number of hunters that were aware of snake species in North Cyprus. The study revealed that 20 hunters knew only 3 species of snakes, 30 hunters were aware of 4 species, 11 hunters of 5 species, 2 hunters knew about 6 species and only 1 about 11 species, respectively.

\section{How many people are aware of snake species present in North Cyprus}

Table 2 shows that Large Whip Snake (Typhlops vermicularis) and Blunt Nosed Viper (Macrovipera lebetina) were known to 70 respondents, Coin Snake (Hemorrhois nummifer) was well known by 64 respondents. Cat Snake (Telescopus fallax) was known 42 respondents. Worm Snake (Typhlops vermicularis), Dwarf Snake (Eirenis levantinus), Grass Snake (Natrix natrix) and Montpellier Snake (Malpolon insignitus) were known by very few respondents. Cyprus Whip Snake (Hierophis cypriensis) and Dahl's Whip Snake (Platyceps najadum) were among the rarest, as only one respondent was aware of them.

\section{How many snake species are venomous?}

Table 3 shows the frequency among hunters about the poisonous snakes. 38 respondents, knew that only 1 snake specie was poisonous, 26 respondents had idea of 2 poisonous snakes whereas 4 respondents knew about 3 species of poisonous snakes. Table 4 shows that Blunt Nosed Viper (Macrovipera lebetina) was known as poisonous snake by all the hunters. 28 respondents thought Coin Snake (Hemorrhois nummifer) as poisonous specie while 10 considered Cat Snake (Telescopus fallax) as poisonous specie as well.

Table 5 and 6 demonstrates lack of knowledge about the snake species in Northern Cyprus. Many hunters had no idea about how many species existed in the country. Majority of people only knew about three and four species of snakes and the 
Table 1 : Knowledge of snake species number

\begin{tabular}{llll}
\hline Number of species & Frequency & Percent & Cumulative percent \\
\hline 3 & 26 & 37.1 & 37.1 \\
4 & 30 & 42.9 & 80.0 \\
5 & 11 & 15.7 & 95.7 \\
6 & 2 & 2.9 & 98.6 \\
11 & 1 & 1.4 & 100.0 \\
Total & 70 & 100 & \\
\hline
\end{tabular}

Table 2: Awareness of snake species

\begin{tabular}{llll}
\hline Names of species & \multicolumn{2}{c}{ Responses } & Percent of Cases \\
\cline { 2 - 4 } & Number of Respondents & Percent & \\
\hline Large Whip Snake (Dolichophis jugularis) & 70 & 26.0 & 100 \\
Worm Snake (Typhlops vermicularis) & 6 & 2.2 & 8.6 \\
Cyprus Whip Snake (Hierophis cypriensis) & 1 & 0.4 & 1.4 \\
Dahls Whip Snake (Platyceps najadum) & 1 & 0.4 & 1.4 \\
Coin Snake (Hemorrhois nummifer) & 64 & 23.8 & 91.4 \\
Dwarf Snake (Eirenis levantinus) & 5 & 1.9 & 7.1 \\
Grass Snake (Natrix natrix) & 7 & 2.6 & 10.0 \\
Cat Snake (Telescopus fallax) & 42 & 15.6 & 60 \\
Montpellier Snake (Malpolonin signitus) & 3 & 1.1 & 4.3 \\
Blunt Nosed Viper (Macrovipera lebetina) & 70 & 26.0 & 100 \\
Total & 269 & 100.0 & 384.3 \\
\hline
\end{tabular}

Table 3: Number of venomous species

\begin{tabular}{llll}
\hline Number & Frequency & Percent & Cumulative percent \\
\hline 1 & 38 & 54.3 & 54.3 \\
2 & 26 & 37.1 & 91.4 \\
3 & 4 & 5.7 & 97.1 \\
4 & 2 & 2.9 & 100.0 \\
Total & 70 & 100.0 & \\
\hline
\end{tabular}

knowledge of remaining seven to eight species were unknown.

Hunters knew that Large Whip Snake (Tvermi cularis) was black in color and quiet large in size, but the problem arose after sexual maturity, when the Large Whip Snake ( $T$. vermicularis) changed its color to light grey. People confused this snake with Blunt Nosed Viper (M. lebetina) and killed them. Coin Snake ( $H$. nummifer) was the most misunderstood specie on the island with Blunt Nosed Viper (M. lebetina). Coin Snake $(H$. nummifer) is widely known by hunters but due to its similarity with Blunt Nosed Viper (M. lebetina) it gets killed most of the time due to similar grey color and less similar pattern. The moment of encounter is sudden so hunters are not able to differentiate it from the Blunt Nosed Viper (M. lebetina) and shoot them. Cat Snake ( $T$. fallax) and Coin Snake (H. nummifer) are also confused with Blunt Nosed Viper (M. lebetina) due to same grey color and similar pattern on their bodies, hence they are shot by hunters.
Table 8 and 9 shows awareness of snake species which are poisonous amongst the hunters. Most of the hunters know about The Blunt Nosed Viper (Macrovipera lebetina) as the only poisonous specie on the island but they only had the knowledge of 3 or 4 species so they mostly confuse the Blunt Nosed Viper (Macrovipera lebetina) with other species, such as Coin Snake (Hemorrhois nummifer), Cat Snake (Telescopus fallax) and Large Whip Snake (Typhlops vermicularis) during sexual maturity, which lead to the problem for all these 4 species. Most hunters are of opinion that Coin Snake (Hemorrhois nummifer) is also poisonous due to its similarity with Blunt Nosed Viper (Macrovipera lebetina). Cat Snake (Telescopus fallax) is also thought to be poisonous by few hunters. Mostly, the color grey and dot, square or ring like patterns are considered as traits of a poisonous snake. Coin Snake (Hemorrhois nummifer) is the main victim due to its similarity with the Blunt Nosed Viper (Macrovipera lebetina). 
Table 4: Venomous snake species

\begin{tabular}{llll}
\hline Snake Specie & \multicolumn{2}{c}{ Responses } & Percent of cases \\
\cline { 2 - 3 } & Number of respondents & Percent & \\
\hline Coin Snake & 28 & 25.9 & 40.0 \\
Cat Snake & 10 & 9.3 & 14.3 \\
Blunt Nosed Viper & 70 & 64.8 & 100.0 \\
Total & 108 & 100.0 & 154.3 \\
\hline
\end{tabular}

Table 5 : Snake as importance factor in our environment

\begin{tabular}{llll}
\hline Idea & Frequency & Percent & Cumulative Percent \\
\hline Agree & 70 & 100.0 & 100.0 \\
\hline \multicolumn{2}{l}{ Table 6: Snake's importance in our environment } & \\
\hline Importance & \multicolumn{2}{c}{ Responses } & \\
\cline { 2 - 4 } & Number of respondents & Percent & Percent of cases \\
\hline Rodent control & 70 & 65.4 & \\
Killing Poisonous snakes & 13 & 12.1 & 100.0 \\
Eating Dead Animals & 13 & 12.1 & 18.6 \\
Medicinal Use & 11 & 10.3 & 18.6 \\
Total & 107 & 100 & 15.7 \\
\hline
\end{tabular}

\section{Do snake have importance in our environment?}

All hunters had idea of snake as an important factor in our environment, yet they were killed by hunters.

\section{How are snake important to our environment?}

All the respondents were aware as snake's control rodent population, 13 respondents believed snake killing other poisonous snakes, 13 respondents believed in snake as eating dead animals and 11 respondents believed in snake used for medicinal use.

\section{Is the population of snakes increasing or decreasing?}

38 respondents believed that the population of snakes were decreasing, 10 people were uncertain about snake population, while 22 hunters believed that the snake population was increasing.

\section{What factors affect the snake population negatively?}

The factors responsible for snake population decrease according to the hunting population. The highest threat according to the data is hunting as 22 respondents believe in hunting is a major threat, 14 respondents believe in pesticides and chemicals as a threat, 17 people believe in habitat loss of snakes as building parks and farms on the snake habitats and destroying their habitat, 13 hunters think of land use by farmers and for construction as a threat and 5 people believe in wild fires as completely whipping the area from snakes and other species.

Most hunters know that the snake population is decreasing day by day and the biggest threat is killing them while hunting. Due to excessive hunters and hunting on a small island, the snakes of every area are getting targeted by the hunters as avoiding them is impossible which leads to hunting as a major threat. The second major threat is habitat loss due to land use. North Cyprus, as the newly developing country, construction of buildings, land use by farmers and other recreational places is on its peak. Mostly they are done without any regard of species habitat and without specie welfare planning's, which leads in loss of habitat of snake species as well. Use of chemicals and pesticides lead to snake poisoning as snakes dwell in fields in search of rodents. Road kill is also a threat as mostly snakes are overrun by vehicles. Wildfire is infrequent, however, it has devastating effect on every specie of that area as it wipeout the whole ecosystem of that area.

\section{How hunting impacting snake population?}

Table 9 shows that 46 respondents believed that hunting negatively affected the snake population, 20 respondents were of opinion that hunting had no impact on snake population, 2 were unsure about the snake population and 2 respondents thought that hunting positively affected then. 
Table 7 : Snake population ratio

\begin{tabular}{llll}
\hline Ratio & Frequency & Percent & Cumulative Percent \\
\hline Decreasing & 38 & 54.3 & 54.3 \\
Uncertain & 10 & 14.3 & 68.6 \\
Increasing & 22 & 31.4 & 100.0 \\
Total & 70 & 100.0 & 100.0 \\
\hline
\end{tabular}

Table 8 : Factors affecting snake population

\begin{tabular}{llll}
\hline \multirow{2}{*}{ Factors } & \multicolumn{2}{c}{ Responses } & Percent of cases \\
\cline { 2 - 3 } & Number of respondents & Percent & \\
\hline Road Kill & 11 & 9.6 & 15.7 \\
Hunting & 22 & 19.3 & 31.4 \\
Pesticides/Chemicals & 14 & 12.3 & 20.0 \\
Land Use & 13 & 11.4 & 18.6 \\
Wild Fires & 5 & 4.4 & 7.1 \\
Habitat Loss & 17 & 14.9 & 24.3 \\
NotDecreasing & 32 & 28.1 & 45.7 \\
Total & 114 & 100 & 162.9 \\
\hline
\end{tabular}

Table 9: Effect of hunting on snake population

\begin{tabular}{llll}
\hline Impact & Frequency & Percent & Cumulative percent \\
\hline Positively & 2 & 2.9 & 2.9 \\
Negatively & 46 & 65.7 & 68.6 \\
Not Sure & 2 & 2.9 & 71.4 \\
No impact & 20 & 28.6 & 100.0 \\
Total & 70 & 100.0 & \\
\hline
\end{tabular}

Hunting is common in Cyprus. Due to lack of species identification, most hunters cannot differentiate between poisonous and non-poisonous snakes. Some hunters think hunting has no impact on snake population as they don't see them usually or as often. Two respondents were not sure about the impact of hunting on snakes while some thought hunting keep a check on their population.

Species awareness can play a key role in controlling snake population. Most hunters were unaware of the fact that 11 species were present on the island as had idea of 3 or 4 species. The confusion between species is also critical as most hunters thought different species as same one. They usually differentiate them by color and pattern, which most of the snakes share the same. Coin Snake (Hemorrhois nummifer), Cat Snake (Telescopus fallax) and Blunt Nosed Viper (Macrovipera lebetina) shares the same color and slightly similar pattern which confuse the hunters to think of them as Blunt Nosed Viper (Macrovipera lebetina) because the attach those traits with the Blunt Nosed Viper(Macrovipera lebetina) . Large Whip Snake (Typhlops vermicularis) is known by every hunter, but the problem arises when at sexual maturity they change the color to slightly grey which majority of hunters don't know, and think of it as Blunt Nosed Viper (Macrovipera lebetina). Blunt Nosed Viper (Macrovipera lebetina) and Large Whip Snake (Typhlops vermicularis) was known by every hunter as it is abundant in number and Blunt Nosed Viper (Macrovipera lebetina) is territorial and did not go away if they see a threat in their territory which makes them more visible than other snakes. Coin Snake (Hemorrhois nummifer) was also known by most of the hunters but they may confuse the Blunt Nosed Viper (Macrovipera lebetina) with the Cat Snake (Telescopus fallax). More than half of the hunters know about Cat Snake (Telescopus fallax) because it can be only differentiated by its eyes. Dwarf Snake (Eirenis levantinus), Grass Snake (Natrix natrix) and Montpellier Snake (Malpolonin signitus) were known by very few which makes them very rare species. Worm Snake (Typhlops vermicularis) is also know by few cause most of hunters think it is a lizard due to its similarity with some lizards. Cyprus Whip Snake (Hierophis cypriensis) and Dahls Whip Snake (Platyceps najadum) are only known by a single respondent which may be a sign that hunters confuse them with other species or these specie is almost at the edge of extinction. So the knowledge can play critical role as stated in study of (Bohm et al., 2013) which stated that affective 
and targeted conservation required detailed information about the species.

The awareness of poisonous and non-poisonous species is crucial as most of the hunters kill the poisonous snakes at sight which cause the non-poisonous species to suffer as well with the poisonous species. There is only one poisonous specie which is Blunt Nosed Viper (Macrovipera lebetina) but most of people confuse other non-poisonous species with Blunt Nosed Viper (Macrovipera lebetina) due to slight similarities in color and pattern. Most of the hunters think Cat Snake (Telescopu sfallax) and Coin Snake (Hemorrhois nummifer) are also poisonous which leads to their killing as well. Some hunters think 3 snake species are poisonous leading to misunderstanding of venomous and non-venomous snake species. All the hunters know that snakes are an important factor in our environment and all of the species play an important role. Every hunter knew about the rodent control by snake population. They also knew that Large Whip Snake (Typhlops vermicularis) lives in the gardens and eat Blunt Nosed Viper (Macrovipera lebetina), it encounters each other. They also believe in snake as eating dead animals and for the use of medicines. Knowing all the benefits of snake population about how they are beneficial for the environment, the hunters still while hunting kill the snakes. The people living near to hilly areas are also more aware then the people living in plain areas about snake species and which are venomous and which are nonvenomous. The knowledge of venomous and non-venomous is also important for hunters as that decide how to their attitude will change with them as stated in.

Most of the hunters believed in the decline of snake population due to various reasons. Among them hunting is the main reason as most of the hunters they kill the snakes while hunting. Habitat loss is also among the main factors as lots of new construction of buildings, parks, road etc. are done without planning about environmental impacts on species near the site. Land use by farming is also impacting the habitats of snakes. Wild fires are not often but when it occurs it wipes out the entire area of all the species giving a massive blow to their numbers. Pesticides and use of other chemicals also impact the snake population as some species lives in farms in search of rodents. Road kills also play a role in snake population decrease as they can easily be overrun by vehicles while crossing the roads. The results match the studies of (Clark et al., 2011) and (McDonald, 2012) which stated these factors as snake specie decline factors.

Most of the hunters believe in hunting as the main problem for decline in snake population. The problem is that North Cyprus is a small island and the number of hunters too much to sustain and there are more licenses issued every few months which means the number will increase in time. There are also not licensed hunters the number are unknown. There are no specific spots for hunting which also increase the threat of affecting every area. Constant hunting also adds to the problem as every time the snake population face hunters throughout the year. As little specie awareness they don't know about venomous and nonvenomous species or get confused and kill them. Some of hunters think they have no impact on snake population is usually because they encounter them especially Blunt Nosed Viper (Macrovipera lebetina). Blunt Nosed Viper (Macrovipera lebetina) is territorial and stay at its spot when encounter a human and don't run away by which they think there is no decrease in their number. Thus the hunters disturb the habitat due to constant hunting which leads to decline in the snake's population as stated in (Bonnet et al., 2016).

\section{References}

Adalsteinsson, S.A., W.R. Branch, S. Trape, L.J. Vitt and S.B. Hedges: Molecular phylogeny, classification, and biogeography of snakes of the Family Leptotyphlopidae (Reptilia, Squamata). J. Zoot., 2244, 6-20 (2009).

Adalsteinsson, H., B. Göçmen, A. Mermer and H. Bahar: An electrophoretic comparison of the venoms of a colubrid and various viperid snakes from Turkey and Cyprus, with some taxonomic and phylogenetic implications. J. Zoot., 1038, 2-5 (2005).

Atatür, M.K. and B. Göçmen: Amphibians and reptiles of Northern Cyprus (frogs and reptiles of Northern Cyprus). Ege University Press, Turkey (2001).

Baboo, B., R. Sagar, S.S. Bargali and H. Verma: Tree species composition, regeneration and diversity within the protected area of Indian dry tropical forest. Tropic. Ecol., 58, 409-423 (2017).

Baier, F., D.J. Sparrow and H.J. Wiedl: The amphibians and reptiles of Cyprus. (Ed.: Chimaira), Germany (2009).

Ballouard, J.M., G., Provost, D. Barré and X. Bonnet: Influence of a field trip on the attitude of schoolchildren toward unpopular organisms: An experience with snakes. J. Herpet., 46, 420-429 (2012).

Bargali, S.S., S.P. Singh and R.P. Singh: Structure and function of an age series of eucalypt plantations in Central Himalaya, I. Dry matter dynamics. Annal. Bot., 69, 405-411 (1992a).

Bargali, S.S., R.P. Singh and S.P. Singh: Structure and function of an age series of eucalypt plantations in Central Himalaya, II. Nutrient dynamics. Anna. Bot., 69, 413-421 (1992b).

Bargali, S.S., R.P. Singh and M. Joshi: Changes in soil characteristics in eucalypt plantations replacing natural broad leaved forests. J. Vegeta. Sci. , 4, 25-28 (1993).

Bargali, S.S. and R.P. Singh: Pinus patula plantations in Kumaun Himalaya. I. Dry matter dynamics. J. Trop. For. Sci., 9, 526-535 (1997a).

Bargali, S.S. and R.P. Singh: Pinus patula plantations in Kumaun Himalaya II. Nutrient dynamics. J. Trop. Forest Sci., 10, 101-104 (1997b).

Bjerke,T. and B.P. Kaltenborn: The relationship of ecocentric and anthropocentric motives to attitudes toward large carnivores. J. Env. Psyc., 19, 415-421 (1999).

Blouin, D.G. and P.J. Weatherhead: Habitat use by black rat snakes (Elapheobsoleta obsoleta) in fragmented forests.J. Ecol., 82, 2870-2890 (2001).

Bohme. W. and H.J. Wiedl: Status and zoogeography of the herpetofauna of Cyprus, with taxonomic and natural history notes on selected species (genera Rena, Coluber, Natrix, Vipera,). Zool. 
Mid. East., 10, 5-42, (1994).

Bonnet, X., G. Naulleau and R. Shine: The dangers of leaving home: Dispersal and mortality in snakes. Bio. Conser., 89, $41-50$ (1999).

Carfagno, G.L.F. and P.J. Weatherhead: Intra specific and inter specific variation in use of forest-edge habitat by snakes. J. Zool., 84, 1400-1452 (2006).

Davey, G.C.L., K. Cavanagh and A. Lamb: Differential aversive outcome expectancies for high-and low-predation fear-relevant animals. J. Behav. Therapy Exper. Psyc., 34, 117-128 (2003).

LoBue, V.J.: The narrow fellow in the grass: Human infants associate snakes and fear. Dev. Scien., 12, 201-207 (2011).

Göçmen, B., C.V. Tok, U. Kaya and M. Tosunoglu: A preliminary report on the herpetofauna of Northern Cyprus. Turkish. J. Zool., 20, 162176 (1996)

Göçmen, B. and W. Böhme: New evidence for the occurrence of the Dice Snake, Natrix tessellates on Cyprus. Zool. Mid. East., 27, 28-34 (2002).

Göçmen, B., H. Arıkan, A. Mermer, B. Langerwerf and H. Bahar: Morphological, hemipenial, and venom electropphoresis comparisons of the levantine viper, Macrovipera lebetina, from Cyprus and Southern Anatolia. Turkish J. Zool., 30, 224-234 (2006).

Göçmen, B., N. Kaşot, M.Z. Yildiz, Sas, I. Akman, B., Yalçinkaya and D.S. Gücel: Results of the herpetological trips to Northern Cyprus. North-West. J. Zool., 4, 139-149 (2008).

Göçmen, B., M.K. Atatür, A. Budak, H. Bahar, M.Z. Yildiz and N. Alpagut: Taxonomic notes on the snakes of Northern Cyprus, with observations on their morphologies and ecologies. Anim. Biol., 59, 1-29 (2009).

Gündüz, S. and Ö. Akkor: The study of university student's awareness and attitude towards environmental education in northern Cyprus. Eur. J. Math. Sci. Tech., 14, 1057-1062 (2018).

Kadeba, O. and E.A. Aduayi: Impact on soils of plantations of Pinus caribaea stands in natural tropical savannas. Forest Ecol. Managem.,13,:27-39 (1985).

Karki, H., K. Bargali, S.S. Bargali, Vibhuti and Y.S. Rawat: Plant diversity, regeneration status and standing biomass under varied degree of disturbances in temperate mixed oak-conifer forest, Kumaun Himalaya. Int. J. Ecol. Environ. Sci., 43, 331-345 (2017).

Kittur, B., S.L. Swamy, S.S. Bargali and M.K. Jhariya: Wildland Fires and Moist Deciduous Forests of Chhattisgarh, India: Divergent ComponentAssessment. J. Fores. Res., 25, 857-866 (2014).

Illseven, S.: Assessment of the impacts of population decline in the town of Guzelyurt on the socio-economic structure of TRNC. J. Anthropl., 23, 335-342 (2016).
Ilseven, S.: Analysis of Garrigue and Maquis communities on the island of Cyprus and comparison with Calabrian pine communities in terms of ecological characteristics. J. Env. Bio., 38, 958 (2017).

Ilseven S. and M. Baştaş: The place of eucalyptus within the vegetation of mesaoria plain (Cyprus) and the views of vegetation geography lecturers. Eur. J. Math. Sci. Tech., 14, 3381-3388 (2018).

Ilseven, S., G. Hıdırer and A. Tümer: Geography of Cyprus. Mins. Educ. North Cyprus (2014).

Kellert, S.R., M. Black., C.R. Rush and A.J. Bath: Human culture and large carnivore conservation in North America. Conserv. Bio., 10, 978-990 (1996).

Milne, J.M., C.Z. Garrison, C.L. Addy, R. McKeown, K.L. Jackson and S.P. Culiffe: Frequency of phobic disorder in a community sample of young adolescents.J. America Acad. Child and Adoles. Psych., 34, 1203-1211 (1995).

Morgan, J.M.: A teoretical basis for evaluating wildlife-related education programs. Amer. Bio. Teac., 54, 153-156 (1992).

Parker, W.S. and W.S. Brown: Species composition and population changes in two complexes of snake hibernacula in northern Utah. Herpetol., 29, 318-326 (1973).

Pooley, J. and M. O'Connor: Environmental education and attitudes: Emotions and beliefs are what is needed. Envir. Behav., 32, 712-723 (2000).

Schätti, B. and U. Utiger: Hemerhophis, a new genus for zamenis socotraegünther, and a contribution to the phylogeny of old world racers, whip snakes and related genera. Rev. Suis. Zool., 108, 929 -938 (2001).

Schätti, B. and H. Sigg: Die Herpetofauna der Insel Zypern. Teil 2: Schildkröten, Echsen. Herpet.,11, 15-23 (1989).

Skogen, K.: Who's afraid of the big, bad wolf? Young people's responses to the conflicts over large carnivores in Eastern Norway. Rur. Sociol., 66, 202-226 (2001).

Stern, P.C., T. Dietz and G.A. Guagnano: The new ecological paradigm in social-psychological context. Env. Behav., 27, 727-743 (1995).

Todd, B.D., J.D., Wilson and J.W. Gibbon: The global status of reptiles and causes of their decline. Ecotoxicology of amphibians and reptiles, second ed. CRC Press., 306, 176-899 (2010)

Wilson, M.A.: The wolf in yellowstone: Science, symbol, or politics? Deconstructing the conflict between environmentalism and wise use. Soci. Natur. Res., 10, 453-465 (1997).

Winne, A.J., C. Scoot, D. Christianoson and S. Lilly: Predation risk affects reproductive physiology and demography of Elk. Env. Sci., 315, 960-960 (2007)

Zinn, H.C. and C.L. Pierce: Values, gender, and concern about potentially dangerous wildlife. Env. Behav., 34, 240-253 (2002). 